\title{
Localizing the first position of a moving stimulus: The Fröhlich effect and an attention-shifting explanation
}

\author{
JOCHEN MÜSSELER and GISA ASCHERSLEBEN \\ Max Planck Institute for Psychological Research, Munich, Germany
}

\begin{abstract}
When subjects are asked to determine where a fast-moving stimulus enters a window, they typically do not localize the stimulus at the edge, but at some later position within that window (Fröhlich effect). We report five experiments that explored this illusion. An attentional account is tested, assuming that the entrance of the stimulus in the window initiates a focus shift toward it. While this shift is under way, the stimulus moves into the window. Because the first phenomenal (i.e., explicitly reportable) representation of the stimulus will not be available before the end of the focus shift, the stimulus is perceived at some later position. In Experiment 1, we established the Fröhlich effect and showed that its size depends on stimulus parameters such as movement speed and movement direction. In Experiments 2 and 3, we examined the influence of eye movements and tested whether the effect changed when the stimuli were presented within a structural background or when they started from different eccentricities. In Experiments 4 and 5, specific predictions from the attentional model were tested: In Experiment 4 we showed that the processing of the moving stimulus benefits from a preceding peripheral cue indicating the starting position of the subsequent movement, which induces a preliminary focus shift to the position where the moving stimulus would appear. As a consequence the Fröhlich effect was reduced. Using a detection task in Experiment 5, we showed that feature information about the moving stimulus is lost when it falls into the critical interval of the attention shift. In conclusion, the present attentional account shows that selection mechanisms are not exclusively space based; rather, they can establish a spatial representation that is also used for perceptual judgment- that is, selection mechanisms can be space establishing as well.
\end{abstract}

In 1923 Friedrich Fröhlich was the first to publish experiments on an error that occurs when subjects are asked to determine where a fast-moving stimulus enters a window: Typically the stimulus is first noticed not at the edge, but at some later position within the window. Though the illusion as such had been reported earlier by the Norwegian astronomer O. Pihl in 1894, Fröhlich was the first to study the effect systematically, so it is aptly termed the "Fröhlich effect." Fröhlich himself attributed the effect to so-called sensation time (Empfindungszeit; see Fröhlich, 1923, 1929) - the time needed to generate the central processing stage of a subjective "sensation." This sensation was considered to be a precondition for conscious perception. Because is takes time to establish the sensation, the perceived mislocation occurs. The effect was amply discussed in the 1930s (see, e.g., Fröhlich, 1925, 1930, 1932; Metzger, 1932; G. E. Müller, 1931; Rubin, 1930), but was neglected

\footnotetext{
We wish to thank Arthur F. Kramer, William C. Schmidt, and an anonymous reviewer for helpful comments and suggestions on a previous draft of the paper, Birgit ABfalg for carrying out the experiments, Claus Gwiggner and Andreas Widmann for preparing the apparatus, Sylvia Raabe for conducting a pilot study, and Heidi John for stylistic suggestions. Correspondence should be addressed to J. Müsseler or G. Aschersleben, Max-Planck-Institut für psychologische Forschung, Leopoldstr. 24, D-80802 München, Germany (e-mail: muesseler@ mpipf-muenchen.mpg.de, aschersleben@mpipf-muenchen.mpg.de, or http://www.mpipf-muenchen.mpg.de/ muesseler).
}

after World War II. In the 1950s, it was considered to be a variant of the metacontrast phenomenon induced by the movement of a stimulus (Alpern, 1953).

For the present contribution, we expand on an interpretation originally developed to explain metacontrast masking (Neumann, 1987; Neumann \& Müsseler, 1990a, 1990b). This interpretation was first developed for stationary stimuli and was then extended to effects appearing with moving stimuli, such as the Fröhlich effect (Müsseler, 1987; Müsseler \& Neumann, 1992). It is based on well-known attentional mechanisms that so far have been mainly studied with stationary displays. However, the empirical properties of visual attention that were revealed in these studies (for reviews, see Allport, 1989; Neumann, 1990; Van der Heijden, 1992) should be equally applicable to situations in which stimuli are in motion.

By analyzing the situation in which the Fröhlich effect occurs in terms of attention shifts, it can be shown that the phenomenon results directly from the well-known properties of visual attention, summarized as follows: (1) A shift of attention can be easily elicited by a stimulus appearing in the retinal periphery (see, e.g., Jonides, 1981; Miller, 1989; H. J. Müller \& Rabbitt, 1989; Theeuwes, 1991). This is valid for stationary as well as for moving stimuli. (2) An attention shift takes time (see, e.g., H. J. Müller \& Findlay, 1988; Sperling \& Reeves, 1980; Tsal, 1983). After attention is directed to a position, reaction time and/or recognition acu- 
ity is improved for a certain interval (see, e.g., Crawford \& H. J. Müller, 1992; H. J. Müller \& Rabbitt, 1989; Posner, 1980; Van der Heijden, Schreuder, \& Wolters, 1985) before it is redirected after a period of at least $300 \mathrm{msec}$ (cf. “inhibition of return”; Posner \& Cohen, 1984). (3) A phenomenal representation of a stimulus is not available before the end of the attention shift. Therefore, locating and pointing to a stimulus requires focal attention being directed to it (see, e.g., Butler \& Currie, 1986; Styles \& Allport, 1986; for an overview, see Van der Heijden, 1992). As a consequence, subjects in a Fröhlich effect experiment have to shift their attention to the stimulus in order to estimate its location.

The stimulus in the Fröhlich effect display is moving, implying that after eliciting the attention shift, it will have moved a certain distance before it is reached by the attentional focus. If the first perceived position of the stimulus is determined after the completion of the focus shift, this stimulus location necessarily deviates from the position of its physical appearance. Or to rephrase the situation: When a moving stimulus enters the window, it initiates a focus shift toward itself. While this shift is under way, the stimulus moves into the window. The first phenomenal (i.e., explicitly reportable) representation of the stimulus will be available at the end of the focus shift. Hence, the stimulus cannot be perceived as it enters the window, but only at a later position. This is what is observed in the Fröhlich effect. ${ }^{1}$

Obviously, shifting attention to a stimulus implies at least some knowledge of the stimulus location prior to the start of the shift. However, this knowledge need not be perfect or-even if it is-it may be corrected and recalibrated after an attentional shift. In order to start shifting attention toward a stimulus, coarse knowledge about its position is sufficient. More precise information can be added during the shift, or "zeroing in" at the target can be accomplished by corrective shifts similar to corrective saccades (see Adam, Paas, Ekering, \& van Loon, 1995). The attentional explanation as applied to the Fröhlich effect assumes that an attention shift can attain its target even if the latter moves during the shift. This requires some degree of flexibility in adjusting the shift after it has begun. In addition, if this explanation is valid, it implies that selection mechanisms are just space based (see, e.g., Tipper, Brehaut, \& Driver, 1990; Tipper, Weaver, Jerreat, \& Burak, 1994); rather, they also establish a spatial representation that is used for perceptual judgment (Müsseler, 1997; Müsseler \& Aschersleben, 1996).

The given explanation of the Fröhlich effect is parsimonious in that it does not require new principles or constructs in addition to those already well known in visual attention. It simply applies them to both stationary stimuli and moving displays. On the other hand, the attentional explanation given in this paper is also potentially fruitful for the study of visual attention. As we will show, an analysis of the Fröhlich effect in attentional terms permits us to test several hypotheses about visual attention. Moreover, this explanation relates two fields of research, motion perception and visual attention. The majority of research combining these two topics has been done on illusory motion; here, attentional mechanisms were applied to explain these phenomena (e.g., Hecht, 1995; Hikosaka, Miyauchi, \& Shimojo, 1993a, 1993b; Horowitz \& Treisman, 1994; Stelmach, Herdman, \& McNeil, 1994; Yantis \& Gibson, 1994). In other studies, moving stimuli were used to investigate the question of whether attention is object based or space based (e.g., Tipper et al., 1990, 1994), or if motion serves as a feature to detect targets in visual search tasks (e.g., Driver, McLeod, \& Dienes, 1992a, 1992b; McLeod, Driver, Dienes, \& Crisp, 1991). Fewer studies made use of attentional mechanisms to explain perceptual errors due to real movements (e.g., Baldo \& Klein, 1995; Hayes \& Freyd, 1995; Müsseler, 1987; Müsseler \& Neumann, 1992).

In the present experiments, we used a computer display to generate the stimuli, in contrast to the mechanical devices of earlier Fröhlich effect studies. The advantage is that the moving stimulus appears unpredictably in time and space on the screen without a starting point that is permanently visible and objectively perceivable (as the window edge would be). Therefore, an estimation of the perceived first location directly reflects the illusion, particularly because the subjects are not aware of their systematic error. However, on a computer-controlled display, a moving stimulus can never be generated continuously. Continuous movement is suggested by successive spatial displacements of a stimulus. This impression of continuous movement is more convincing the smaller the spatial displacement and the higher the vertical retrace rate of the monitor.

The following five experiments examined whether the attentional account described above is valid for moving stimuli like those generating the Fröhlich effect. Experiment 1 was designed to establish the existence of the Fröhlich effect with a computer-generated presentation and to test whether its size depends on stimulus parameters such as movement speed and movement direction. In Experiments 2 and 3, we examined the influence of eye movements, structural background, and different eccentricities of the starting position. In Experiments 4 and 5, we checked further predictions of the attentional account. In the General Discussion, the findings are summarized and alternative explanations of the Fröhlich effect are discussed.

\section{EXPERIMENT 1}

One characteristic feature of the Fröhlich effect is its dependence on movement speed: The higher the velocity of the stimulus, the larger the Fröhlich effect (Fröhlich, 1923; see also Müsseler \& Neumann, 1992). This result is in accordance with our attentional account in that-during an attention shift that takes a certain time - a faster stimulus covers a greater distance than a slower stimulus. Thus, at the end of the focus shift, the perceived first position of the stimulus should be dependent on movement speed. In the first experiment, we tried to establish the existence of the Fröhlich effect with a computer-generated presentation and to replicate its dependence on movement speed. Further, we examined whether the Fröhlich effect varies with respect to movement direction - that is, whether the 


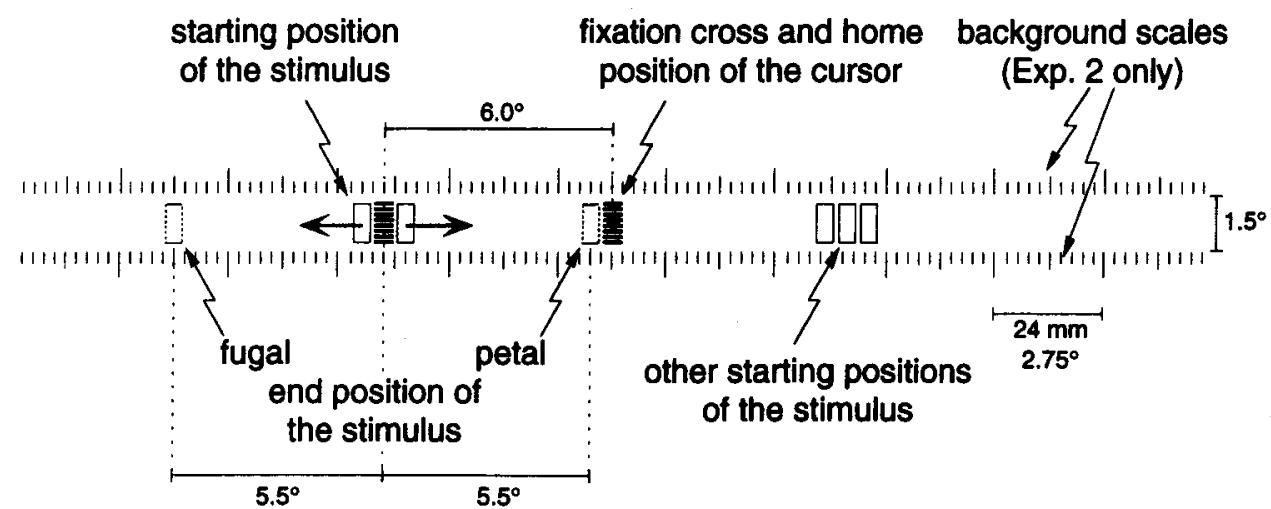

Figure 1. Stimulus presentation in the experiments. Subjects fixated a cross in the middle of the screen and a moving stimulus appeared to the left or the right of the fixation cross. Subjects' task was to move the cursor to the position where they had seen the stimulus for the first time. Background scales were presented in Experiment 2 only.

effect discriminates between the stimulus moving toward or away from the fovea (foveopetal vs. foveofugal movements). The results were contrasted with a stationary stimulus condition in which a single flash was presented at the starting position only. The purpose of this control condition was to determine subjects' precision in localizing spatial positions.

\section{Method}

Apparatus and Stimuli. The experiments were carried out on a laboratory computer (Rhothron rho-prof 200) and a high-speed 20in. monitor with black-on-white projection (Philips C2082DAS/II), The monitor's luminance was approximately $41 \mathrm{~cd} / \mathrm{m}^{2}$, and the rest of the room was dimly lit. As moving stimuli we used horizontally striped rectangles $\left(0.5^{\circ}\right.$ wide $\times 1.0^{\circ}$ high $)$ that consisted of 16 equally sized black-and-white lines. Thus, their luminance was reduced to $19 \mathrm{~cd} / \mathrm{m}^{2}$. Stimuli were presented randomly at two different starting positions of about $6^{\circ}$ to the left or to the right of a central fixation cross. The exact starting position varied $6^{\circ} \pm 0.5^{\circ}$ to prevent subjects from always estimating the same position (Figure 1).

The stimulus movement was induced by shifting the rectangle $0.275^{\circ}$ to the left or right with every vertical retrace of the monitor. In the present experiment, two vertical retrace rates were used-52 and $160 \mathrm{~Hz}$. The movement distance made $5.5^{\circ}$ in each direction; that is, absolute movement times were $383 \mathrm{msec}$ for the slow and $125 \mathrm{msec}$ for the fast retrace rate. Therefore, different movement velocities were induced by using identical spatial stimulations but different temporal presentation rates.

The subject's head was placed on a chin and forehead rest $50 \mathrm{~cm}$ in front of the monitor. For subjects' judgments, an adjustment cursor was used that was identical to the stimulus and whose home position was on the fixation cross. Subjects could move this cursor horizontally with the computer mouse.

Design. Stimuli moved randomly to the right or the left starting from the (randomly selected left or right) peripheral starting position; that is, movements were directed either toward or away from the foveal fixation cross (foveopetal vs. foveofugal movements). In the control condition, each stimulus was presented for one vertical retrace only (single-flash presentations). These conditions were presented in random order. The two speed conditions (retrace rates of $52 \mathrm{vs}$. $160 \mathrm{~Hz}$ ) were presented blockwise; that is, half of the subjects were first confronted with the $52-\mathrm{Hz}$ condition and then with the $160-\mathrm{Hz}$ condition; for the other half of the subjects this sequence was re- versed. Forty-eight repetitions per subject were gathered within each cell of the design. In total, the subjects underwent 288 trials.

Procedure. The central fixation cross with the home position of the cursor was visible throughout the experiment. Each trial began with an auditory warning signal ( $1000 \mathrm{~Hz}$ for $50 \mathrm{msec}$ ), and after $1 \mathrm{sec}$ the stimulus appeared to the left or to the right of the fixation cross. The instruction stressed that subjects should concentrate on the fixation cross during the whole movement. After stimulus presentation, subjects had to move the cursor to the position where they had perceived the beginning of the movement (or to where they had seen the single-flash presentation).

During the adjustment phase of the cursor, eye movements were allowed. After the perceived position was localized, a mouse buttonpress confirmed the adjustment, and the cursor was moved back to the home position. The experimental procedure was self-paced; that is, the next trial was initiated only after a further mouse click, with a programmed $1-\mathrm{sec}$ delay. To familiarize subjects with the task, a training block consisting of 15 trials was presented at the beginning. The experiment lasted about $30 \mathrm{~min}$, including short breaks.

Subjects. Nine female and 2 male students at the University of Munich who ranged in age from 19 to 33 years $(M=26.8$ years ) were paid to participate in the experiment. They reported normal or corrected-to-normal vision.

\section{Results}

As a dependent variable, the perceived mislocation was computed as the difference between the adjusted and the real first position of the stimulus with respect to movement direction. Positive values stand for errors in the direction of the movement. In the flash condition, negative values indicate more foveal adjustments.

Mean values were computed for every subject and each condition separately. The results of the experimental conditions were entered into a $2 \times 2$ repeated measures analysis of variance (ANOVA) with the factors movement speed ( $52 \mathrm{vs.} 160 \mathrm{~Hz}$ ) and movement direction (foveopetal vs. foveofugal). As expected, the Fröhlich effect - that is, the amount of mislocation-was greater under conditions with higher movement speed $\left[F(1,10)=8.81, M S_{\mathrm{e}}=21.51\right.$, $p=.014$; see Figure 2]. Additionally, an effect of the movement direction was observed; the mislocation was 


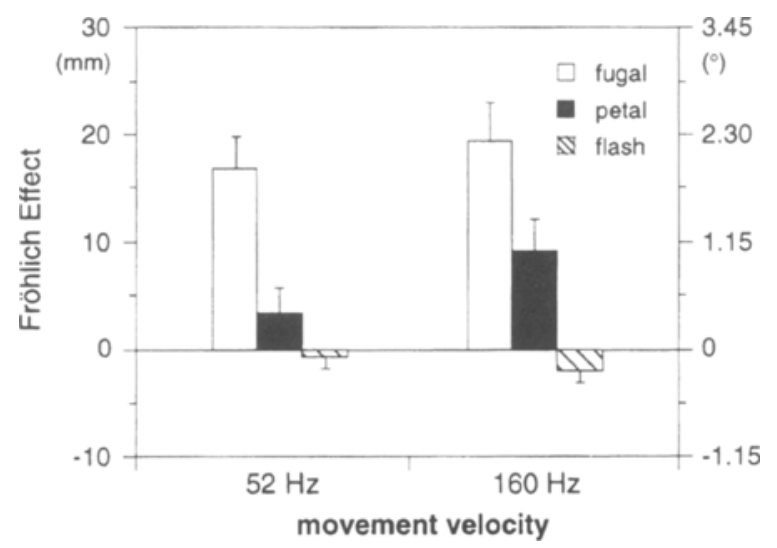

Figure 2. Mean mislocations and standard errors (between subjects) of the first position of a moving stimulus in the direction of the movement (size of Fröhlich effect). In the flash condition, negative values indicate more foveal adjustments (Experiment 1, $N=$ 11; each bar corresponds to 48 observations for each subject).

greater with foveofugal movements than with foveopetal movements $\left[F(1,10)=11.42, M S_{\mathrm{e}}=135.28, p=.007\right]$. No interaction between these variables was found.

The localizations of the single-flash presentations revealed that subjects were very good at localizing nonmoving stimuli. There was only a small tendency toward more foveal judgments, and this tendency increased if the presentation time was determined by one vertical retrace in the $160-\mathrm{Hz}$ condition (presentation time $6.25 \mathrm{msec}$ ) as compared with the $52-\mathrm{Hz}$ condition (presentation time, $19.15 \mathrm{msec}, t=2.50, p=.032$, two-tailed). ${ }^{2}$

\section{Discussion}

In the present experiment, we established the existence of the Fröhlich effect by using a computer-generated presentation. Subjects tended to make mislocation errors in the direction of the movement when they were asked to judge the starting position of a fast-moving stimulus, whereas they were quite precise in judging a stationary stimulus flash. In addition to this general finding, there were three main results that should be discussed: (1) the dependence of the Fröhlich effect on movement speed, (2) the foveopetalfoveofugal difference, and (3) the results of the control condition.

As expected, the Fröhlich effect increased with movement speed, as described earlier by Fröhlich (1923), and as predicted by our attentional account (Müsseler \& Neumann, 1992). During an attention shift, a faster stimulus covers a greater distance than does a slower stimulus, and the amount of mislocation increases correspondingly.

Before we attempt to explain the second result-the foveopetal-foveofugal difference - we focus on the results of the control condition. The single flash in the control condition produced a small but reliable tendency for more foveal mislocations (at least in the $160-\mathrm{Hz}$ condition). Similar or closely related findings have been reported by, for example, Hagenaar and Van der Heijden (1997); Mate- eff and Gourevich (1983); Müsseler, Van der Heijden, Mahmud, Deubel, and Ertsey (1998); O'Regan (1984); Rose and Halpern (1992); and others. It is beyond the scope of the present paper to account for this effect (for an overview, see Skavenski, 1990), but this tendency modified the results observed under the experimental conditions. As noted, the Fröhlich effect was significantly larger with foveofugal movements than with foveopetal movements. This result was modulated by the general foveal tendency in the following way. Imagine that there is no Fröhlich effect with moving stimuli at all, but only the tendency for foveal mislocations. In that case, foveopetal movements should show a mislocation in the direction of the movement (similar to the Fröhlich effect), and foveofugal movements should show a mislocation in the opposite direction (contrary to the Fröhlich effect). Thus, in our experiment it might be that for foveopetal movements the amount of the Fröhlich effect is overestimated whereas for foveofugal movements it is underestimated, resulting in an even larger difference between conditions. On the other hand, the mislocations of the single flash are relatively small compared with the differences between the mislocations of the foveopetal and foveofugal movements.

At first sight, this foveopetal-foveofugal difference is in accordance with the old idea that visual attention acts like a spotlight on a stage whose contents receives prioritized processing and that the spotlight moves with constant velocity from one position of the visual field to another (see, e.g., Posner, 1980; Posner \& Cohen, 1984; Shulman, Remington, \& McClean, 1979; Tsal, 1983). In the foveopetal condition, the stimulus movement and the attention shift toward it are in opposite directions, "going toward and meeting" at some point. In the foveofugal condition, they follow the same direction, and the shift has to "catch up" with the stimulus movement. If there were a spotlight moving in a continuous fashion through the visual field, the "catching-up" process would take longer than the "goingtoward" process of spotlight and stimulus; thus the Fröhlich effect should be greater with foveofugal movements than with foveopetal movements. This is indeed reflected in the results. However, although this interpretation would be a plausible one, more recent findings cast serious doubts on the spotlight idea of attentional focus (e.g., Chastain, 1991; Driver \& Baylis, 1989; Müsseler, 1994; Shepherd \& Müller, 1989; Sperling \& Weichselgartner, 1995). In Experiments 3 and 4 , we return to that assumption and put it to another test by manipulating the distance between the focal starting position and the position from which the stimulus is starting.

The foveopetal-foveofugal finding might also reflect low-level processing differences rather than central attentional ones. It has been discussed, for example, that the retinal system and its subsequent processing units might have a lower sensitivity threshold for foveofugal movements than for foveopetal movements (Mateeff \& Hohnsbein, 1988; Mateeff et al., 1991). Furthermore, an additional location error may originate from differences in the eccentricity: The adjustment of the mouse cursor was not as 


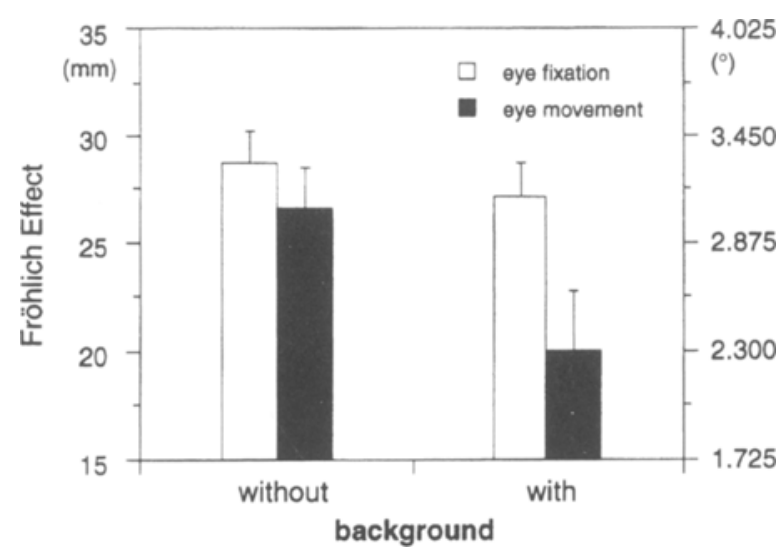

Figure 3. Mean mislocations and standard errors (between subjects) of the first position of a moving stimulus in the direction of the movement (size of Fröhlich effect, Experiment 2, $N=11$; each bar corresponds to about 48 observations for each subject).

much in the retinal eccentricity with foveopetal movements as with foveofugal movements. This may increase an error tendency and, again, point to a low-level explanation. We return to this issue in Experiment 3, in which we tested whether eccentricity influenced the amount of the mislocation. In Experiment 2, we examined two further variables that might have caused the mislocations - the influence of eye movements and the effect of a structured visual background.

\section{EXPERIMENT 2}

In Experiment 1, it was emphasized that subjects focus on the fixation cross during stimulus movements, and at least with the high-movement speed, the presentation time of the stimulus was by far too short $(125 \mathrm{msec})$ to initiate eye movements or even capture the stimulus with the eyes. However, this does not exclude the possibility that the observed mislocations were influenced or even evoked by subsequent eye movements, especially since subjects were free to move their eyes while adjusting the cursor. If subjects executed saccades in the adjustment phase, then the internal spatial map was updated with respect to the new fixation. It is possible that this updating is susceptible to errors that might grow, as it were, into the Fröhlich effect. Even though the concrete error mechanism would need specification, in this case the effect had to be located in the adjustment phase, with eye movements as the critical premise. To test this response-bias assumption, in the present experiment we introduced two eye-movement instructions for the adjustment phase-one to fixate the cross throughout and the other to move the eyes on stimulus presentation, which meant that eye movement did not start before the end of the stimulus movement because of the short presentation time $(125 \mathrm{msec})$. If the response-bias assumption is valid, the size of the Fröhlich effect should be sensitive to this experimental variation.

A related question results from the observation that saccadic eye movements are known to be more accurate in a structured visual context than with a homogeneous background (see, e.g., Collewijn, Erkelens, \& Steinman, 1988; Lemij \& Collewijn, 1989). One possible reason is that a target is easier to locate if its position is determined relative to its context. If this is true for moving stimuli as well, then this offers another variable that might influence the Fröhlich effect: it may be smaller when stimuli are presented against a structural background than against a nonstructured background.

\section{Method}

Stimuli. Stimulus presentation was the same as in Experiment 1 with the following exceptions. Only foveofugal movements were presented with a monitor-retrace rate of $160 \mathrm{~Hz}$. The background consisted of two $\mathrm{cm}$ scales, with one scale appearing just above the movement course of the stimulus, the other scale just below (separated by $1.5^{\circ}$; see Figure 1 ).

Control of eye-movement instructions. The horizontal position of the left eye was monitored with a head-mounted, infrared, light-reflecting eyetracking device (Skalar Medical B.V., IRIS Model 6500). As in Experiment 1 the subject's head was fixed by means of a chinrest $50 \mathrm{~cm}$ in front of the monitor. The eye-movement modulated signal was bandpass, demodulated, and low-pass filtered (DC $100 \mathrm{~Hz}, 3 \mathrm{~dB}$ ) and then digitized at a rate of $250 \mathrm{~Hz}$ with a PC (via a DataTranslation card, DT 2821). Calibration of the monitor was accomplished by having the subject fixate at seven evenly spaced digits across the screen.

Saccadic eye movements were detected by analyzing the eyemovement signal so that we were able to discover at least the occurrence of saccades larger than $1^{\circ}$ of visual angle. If a saccade was detected during a trial under the fixation instruction (see below), the corresponding data were excluded from further analyses. Trials under the eye-movement instruction were excluded if no saccades were detected. Exclusions were necessary in $9.2 \%$ of the trials.

Design and Procedure. The experiment was run in four successive blocks resulting from the factorial combinations of "with versus without background" and "eye-fixation versus eye movement instruction." After initiating a trial by pressing a mouse button, subjects in the eye-fixation condition had to concentrate on the fixation cross and to hold fixation in the cursor's adjustment phase. Between trials, subjects were free to move their eyes and to relax whenever they wanted. This was also emphasized in the eye-movement condition, in which subjects were instructed to move their eyes toward the first position of the stimulus on presentation of the moving stimulus.

The sequence of blocks was randomized for each subject. Altogether, subjects were presented with 48 trials within each block. The entire experiment lasted approximately $75 \mathrm{~min}$, including training trials.

Subjects. Eleven subjects were paid to participate. Their mean age was 24.5 years, with a range of 2038 years.

\section{Results}

Under conditions without a structured background, the Fröhlich effect remained nearly unchanged, independently of whether the instruction was to maintain fixation or to move the eyes toward the first position of the stimulus. This was true under the condition with a background presentation as well, but only when the eyes were fixated; under the condition in which eye movements were combined with a structured background, the effect was smaller (Figure 3).

This result was confirmed by the significant interaction between both factors $\left[F(1,10)=10.71, M S_{\mathrm{e}}=6.41, p=\right.$ 


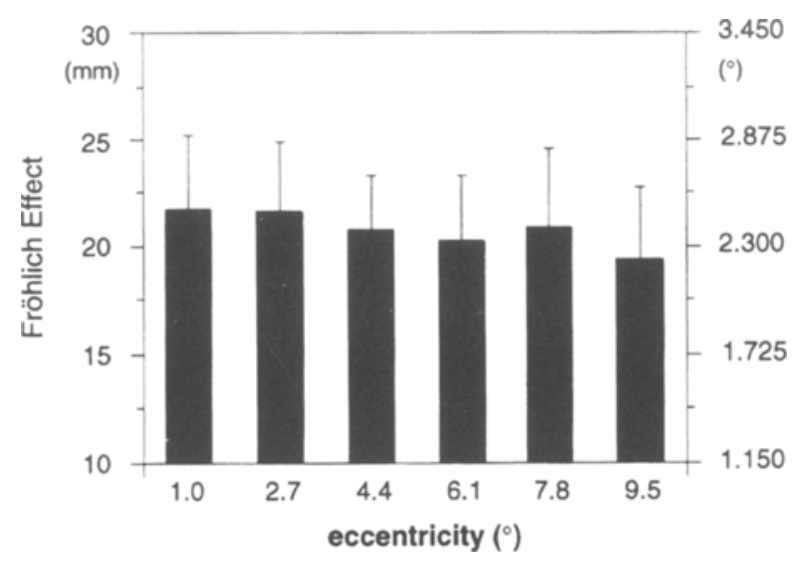

Figure 4. Mean mislocations and standard errors (between subjects) of the first position of a moving stimulus in the direction of the movement (size of Fröhlich effect, Experiment 3, $N=12$; each bar corresponds to $\mathbf{4 0}$ observations for each subject).

.008]. Additionally, the main effect of background was significant $\left[F(1,10)=24.78, M S_{\mathrm{e}}=7.57, p=.001\right]$, but a subsequent Scheffé test showed that the only significant difference between means was produced by the combined condition - that is, with eye movements and a structured background (critical Scheffé difference of $3.35 \mathrm{~mm}$ and $0.38^{\circ}, p<.01$ ). All other comparisons among means were not significant (each $p>.05$ ).

\section{Discussion}

The results clearly indicate that the Fröhlich effect does not originate from factors determined by eye movements and that it does not disappear when a structured visual background is presented. It is, however, reduced when these two components are combined. A possible explanation comes from the well-known finding that saccades usually undershoot their target by approximately $10 \%$ (see, e.g., Becker \& Fuchs, 1969; Deubel, Wolf, \& Hauske, 1982; Henson, 1979), but this undershooting is reduced to $5 \%$ or less when a structured visual background is presented (Collewijn et al., 1988; Lemij \& Collewijn, 1989). Obviously this accuracy increase might influence possible location tasks and thus decrease the Fröhlich effect. On the other hand, it did not lead to an elimination of the effect in the present experiment.

\section{EXPERIMENT 3}

The difference in the amount of the mislocation under foveofugal and foveopetal conditions (Experiment 1) might be explained under an assumption that the focus of attention moves continuously through the visual field. As argued in the discussion of Experiment 1, the "catchingup" process (with foveofugal stimulus movements) is assumed to take longer than the "going-toward" process (with foveopetal stimulus movements) of focus and stimulus. However, as already mentioned, this spotlight assumption is controversial.
The present experiment was designed to test this assumption by manipulating the distance between the assumed starting position of the focus (i.e., the fixation point) and the position from which the moving stimuli were starting. With the spotlight assumption, it should take more time to reach more eccentric starting positions than less eccentric ones. Thus the Fröhlich effect should increase as well. The alternative attentional account assumes that the attentional focus does not move in a continuous manner through the visual field; rather, the attention shift is supposed to be time invariant (Eriksen \& Murphy, 1987; Kwak, Dagenbach, \& Egeth, 1991; Müsseler, 1994; Remington \& Pierce, 1984). In that case, the amount of the mislocation should be independent from any variation of eccentricity.

\section{Method}

Stimuli. As in the previous experiment, only foveofugal movements were presented with a monitor-retrace rate of $160 \mathrm{~Hz}$. Relative to the fixation point the stimuli could start at eccentricities of $2.7^{\circ}, 4.4^{\circ}$, and $9.5^{\circ}$ in the left visual field and $1.0^{\circ}, 6.1^{\circ}$, and $7.8^{\circ}$ in the right visual field.

Design and Procedure. All subjects were presented the six different starting positions in a completely randomized sequence. Subjects were confronted with 40 trials per condition. The entire experiment lasted approximately $30 \mathrm{~min}$.

Subjects. Twelve subjects were paid to participate. Their mean age was 27.5 years, with a range of 22-38 years.

\section{Results and Discussion}

A one-way ANOVA with repeated measures did not show any effect of different eccentricities $[F(5,55)=0.26$, $M S_{\mathrm{e}}=35.94, p=.935$; see Figure 4]. An additional trend analysis also failed to indicate a systematic tendency toward a linear or higher order relationship in the means (all $p \mathrm{~s}>$ .25). Thus, the time needed for the focus shift seems to be somewhat independent from the eccentricity of its end position. We have to conclude that the focus shift takes some time to reach the moving stimulus after being initiated by its appearance, but that this time is constant for different physical distances. On the other hand, a shift in terms of a continuous linear movement-that is, with constant velocity through the visual field (as assumed by the spotlight metaphor) - can be ruled out for the present data and, as a consequence, for the foveofugal-foveopetal difference reported in Experiment 1 as well. We return to this point in the General Discussion.

In the present experiment, the final position of the assumed attention shift was varied. In the following experiments we examined the extent to which the time needed for the shift is independent of its starting position.

\section{EXPERIMENT 4}

The aim of this experiment was to provide further support for our attentional explanation of the Fröhlich effect by varying the starting position of the attention shift. Our assumption is based on the idea that the appearance of a moving stimulus initiates a focus shift toward the stimulus, and while this shift is under way, the stimulus moves into the scene. Under this assumption, the processing of the mov- 


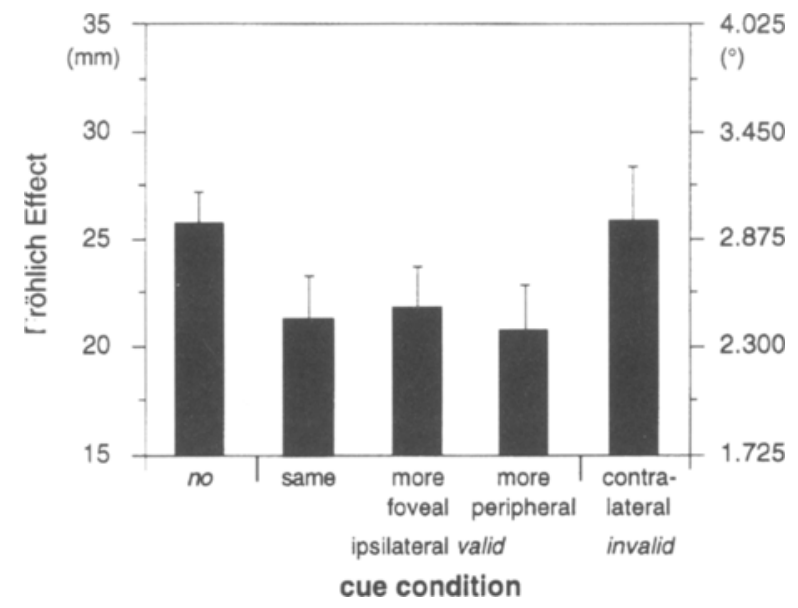

Figure 5. Mean mislocations and standard errors (between subjects) of the first position of a moving stimulus in the direction of the movement (size of Fröhlich effect). Bars represent different cue conditions (Experiment 4, $N=16$; each bar corresponds to 60 observations for each subject).

ing stimulus should benefit from a preceding peripheral cue that announces the following movement and thus induces a preliminary focus shift to the position where the stimulus will appear. As a consequence, the Fröhlich effect should be reduced. This is assumed for a cuing condition in which the cue provides valid spatial information.

On the other hand, there are specific predictions for conditions with an invalid cue as well. If the cue is invalid (e.g., contralateral to the position where the moving stimulus will appear) and if we assume that the time needed for the attentional focus shift is somewhat independent of physical distances, then the size of the Fröhlich effect should be the same as when there is no cue. Furthermore, the Fröhlich effect should be greater under both the no-cue condition and the invalid-cue condition than in valid-cue conditions.

\section{Method}

Stimuli. Stimulus presentation was based on that in the previous experiments. The cue consisted of two horizontally arranged bars, each $0.62^{\circ}$ long and separated vertically by $1.99^{\circ}$. The upper bar appeared just above the movement course of the stimulus, the lower one just below it. The cue appeared for $25 \mathrm{msec}$ with a $125-\mathrm{msec}$ stimulus onset asychrony (SOA) between cue and moving stimulus. This time interval usually induces peripheral cuing effects that improve performance in identification tasks or reaction time tasks (see, e.g., Müsseler, 1994; Van der Heijden et al., 1985).

Design and Procedure. With respect to the fixation cross, the cue and the stimulus were presented either in the same or in the opposite visual field (ipsilateral-and contralateral-cue conditions, respectively). In the ipsilateral condition, the cue was spatially valid. Here, three minor eccentricity deviations were presented: (1) The cue appeared exactly at the horizontal position where the stımulus started; (2) the cue appeared $0.55^{\circ}$ shifted to the fovea; or (3) the cue appeared $0.55^{\circ}$ shifted to the periphery. These minor cue deviations from the exact starting positions were necessary; otherwise subjects could choose the strategy of adjusting the mouse cursor to the cue position only.

The invalid-cue condition was specified by presentıng the cue at the contralateral position; that is, the cue and the moving stimulus were given with identical eccentricity but on either side of the fixation cross. Further, a control condition was introduced with no cue at all. Each of these five conditions (three valid ipsilateral positions, one invalid contralateral position, and one no-cue condition) was presented with equal probability. Therefore, a valid cue appeared in $60 \%$ of the trials.

The experimental procedure was basically the same as in the previous experiments. Subjects were instructed to ignore the cue and to concentrate on the fixation cross until the end of the movement. Altogether, subjects were confronted with 60 trials per condition in a completely randomized order.

Subjects. Sixteen subjects were paid to participate in the experiment. Their mean age was 26.4 years, with a range of $20-37$ years.

\section{Results}

A one-way ANOVA with repeated measures revealed a significant difference between conditions $[F(4,60)=$ $\left.11.35, M S_{\mathrm{e}}=9.02, p<.001\right] .^{3}$ The main finding was that the Fröhlich effect was clearly smaller under conditions with valid (ipsilateral) cues than under conditions with invalid (contralateral) cues or with no cue at all (Figure 5).

A comparison among means using a Scheffé test exhibited no differences between the valid-cue conditions $(p>.25)$. Furthermore, the difference between the invalid-cue and the no-cue conditions was not statistically significant $(p>.25)$. The only reliable differences were those between the valid-cue conditions, on the one hand, and the invalid-and no-cue conditions, on the other hand (critical Scheffé difference of $3.38 \mathrm{~mm}$ and $0.39^{\circ}$, respectively; $p<.05)$.

\section{Discussion}

The main finding is that under conditions with a valid cue, the Fröhlich effect was clearly smaller than in conditions with an invalid cue or no cue at all. In attentional terms that means: Under conditions in which no attention shift was needed (valid-cue conditions), there was less mislocation than in conditions in which the shift could be initiated only by the appearance of the moving stimulus (invalid- and no-cue conditions). This has to be interpreted in such a way that the valid cue already initiated a focus shift to the correct position and therefore resulted in a reduction of the Fröhlich effect.

Nevertheless, the reduction was rather small and the Fröhlich effect was far from vanishing altogether. One reason might be that the time between the appearance of the cue and the onset of the stimulus (with an SOA of $125 \mathrm{msec}$ ) was too short to complete the attention shift. Although latency studies have indicated an advantage with a 100 msec cuing period (e.g., Crawford \& H. J. Müller, 1992; Müsseler, 1994), identification task studies point to an optimal peripheral cuing time of $175 \mathrm{msec}$ (e.g., H. J. Müller \& Rabbit, 1989). In any case, in our experimental situation it is possible that the attention shift was still under way when the stimulus showed up. In that case, of course, the Fröhlich effect could be merely reduced. Possibly, too, an attention shift is not completely decoupled from the feature analysis. Because cue and stimulus are two different objects with different features, they could need at least minimally divergent attentional allocations. The fact that these 
allocations are not only specified by the spatial position of cue and stimulus may prevent the effect from vanishing, too. We return to that point in the General Discussion.

Taken together with the results obtained in Experiment 3 , in which no influence of eccentricity on the amount of mislocation was observed, we now can conclude that the spotlight idea cannot account for effects observed with stimuli in motion: Because there was no difference between the invalid-cue and the no-cue conditions in the present experiment, it would seem that the attention shift does not "move" continuously from the cue toward the position of the moving stimulus (see Chastain, 1991; Shepherd \& Müller, 1989); otherwise the Fröhlich effect would have been greater in the invalid-cue condition. The results indicate that directing attention leads to an enhanced and prioritized processing at the cued position, which is independent of the previously focused position in space and time (Müsseler, 1994; cf. Sperling \& Weichselgartner, 1995).

\section{EXPERIMENT 5}

A further implication of our attentional account was tested in the last experiment: Feature information about the moving stimulus that falls into the critical interval of the attention shift should get lost. Because the assumption is that the first reportable representation of the stimulus is not available before the focus shift is completed, any modification of the stimulus at the beginning of the movement should go unnoticed. To test this implication, subjects had to detect a transient modification of the stimulus at three different movement phases - at the beginning, somewhere in the middle, and at the end of the physical movement. According to our attentional account, it is predicted that a modification at the beginning of the movement is harder to detect than a modification occurring at the end of the movement. This is because at the end of the movement the attention shift should be completed and, therefore, the stimulus is focused. As a consequence, any stimulus modification should be easier to report than one occurring during the focus shift.

\section{Method}

Apparatus and Stimuli. In the present experiment, a black rectangle $\left(0.5^{\circ} \times 1.0^{\circ}\right)$ moved in foveofugal direction starting from $6^{\circ}$ eccentricity. As before, the movement was induced by shifting the rectangle $20 \times 0.275^{\circ}$ to the left or right with every vertical retrace of the $160-\mathrm{Hz}$ monitor. However, the black rectangle could now turn into an equally sized but striped rectangle at different phases of the movement. This stimulus modification consisted of three black-onwhite stripes (each $0.12^{\circ}$ ) that were horizontally arranged at the bottom, in the middle, and at the top of the rectangle and presented for two vertical retraces $(13 \mathrm{msec})$ instead of the black rectangle.

To record subjects' detection performance, two microswitches served as response keys, pressed by the index and middle fingers of the right hand. Otherwise, the apparatus and stimulus presentation were identical to those in the previous experiments.

Design. The black rectangle could turn for $13 \mathrm{msec}$ into the striped rectangle with the $2 \mathrm{nd}$, the $7 \mathrm{th}$, or the $18 \mathrm{th}$ vertical retrace (i.e., at $0.55^{\circ}, 1.925^{\circ}$, or $4.95^{\circ}$ movement distance, respectively). The modification of the stımulus happened within one trial once only. The alteration with the 2 nd vertical retrace occurred at the very be- ginning of the movement, whereas the alteration with the 18 th vertical retrace occurred almost at the end of the physical movement. The alteration with the 7 th vertical retrace fell into the critical phase of the subjective appearance of the stimulus. Note that in order to produce comparable conditions, all alterations were placed within the movement; that is, in case of the alteration at the beginning ( $2 \mathrm{nd}$ ) and at the end (18th) of the movement, the original black stimulus was the first or the last one to be presented. In addition, there was a control condition in which no change of the stimulus occurred. Each subject was presented with each condition in a repeated measures design.

Procedure. The task of the subjects was to detect the striped rectangle during the stimulus movement. After the presentation they had to answer by pressing a "yes" or a "no" key, respectively. Each subject performed a total of 288 trials. In half of the trials the stimulus alteration was omitted; thus the probability for the presentation of the striped rectangle was 0.5 . Subjects were informed about this probability at the beginning of the experiment. The trials with the stimulus alteration were equally distributed among the remaining conditions. The order of presentation was completely randomized.

The instruction stressed subjects' concentration on the fixation cross. To familiarize the subjects with the task, a training block was presented at the beginning. The entire experiment lasted about $45 \mathrm{~min}$, including short breaks.

Subjects. Seventeen adults with an average age of 26.2 years (range $=20-37$ years) served as paid subjects. Because a minimal error rate per subject is necessary to analyze differences between conditions, 2 subjects were dropped from the final analysis (error rate $<5 \%$ ).

\section{Results}

Probabilities correct per subject and condition were entered as the dependent variable into a one-way ANOVA, yielding significant differences between the stimulus alteration positions $\left[F(2,28)=7.49, M S_{\mathrm{e}}=.016, p=.002\right]$. As can be seen from Figure 6, the detection probability of a stimulus alteration at the beginning of the movement (with the 2 nd vertical retrace, $p=.701$ ) was clearly lower than the probability at the end of the movement (with the 18th vertical retrace, $p=.872$ ). Further, the latter probability hardly differed from the probability correct resulting from the control condition, in which no alteration occurred $(p=$ .842 -i.e., the false alarm rate was at $p=.158$ ). A Scheffé test confirmed these findings (critical difference of .152, $p=.01$ ). The detection probability of the stimulus alteration at the 7th vertical retrace was in between $(p=.740)$; not statistically different from the 2 nd retrace condition but was different from the condition in which the stimulus alteration occurred at the end of the movement (critical difference of .119, $p=.05$ ).

\section{Discussion}

The results of this last experiment fully support the predictions deduced from our attentional account. When a modification of a moving stimulus occurred at the beginning of the movement, it was much harder to detect than if it occurred at the end of the movement, with the middle condition lying in between. This finding supports the assumption that during the attention shift, feature information about the moving stimulus is lost. At the end of the movement, the attention shift is completed and therefore the stimulus is focused. Under this condition, any stimulus modification is easy to report, which is reflected in our data. 


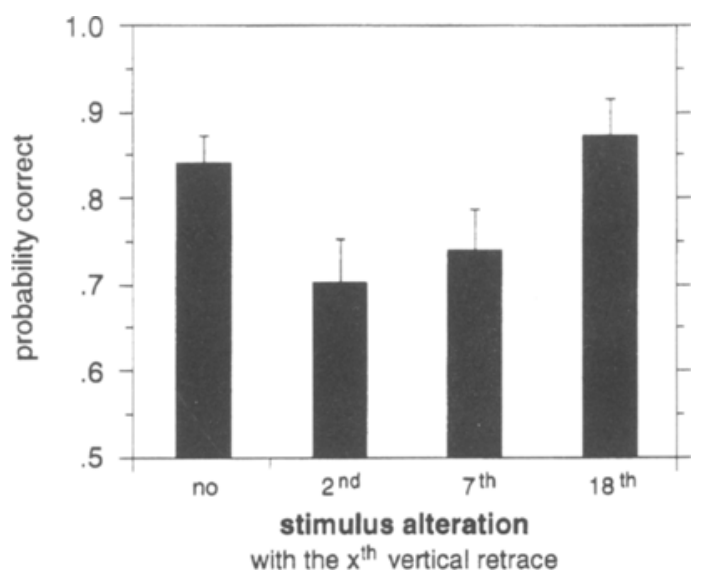

Figure 6. Mean probabilities correct and standard errors (between subjects) in detecting a stimulus alteration in different phases of the movement. Chance level is .5 (Experiment 5, $N=15$; probabilities based on 144 judgments from each subject for the no-alteration condition and 72 judgments for each of the remaining conditions).

Note that we used foveofugal movements always starting at the same position $\left(6^{\circ}\right)$. The stimulus alterations at the end of the movement (at about $11^{\circ}$ ) were much more peripheral than the ones at the beginning (at about $6.5^{\circ}$ ). If attentional mechanisms were neglected, the reverse result would be plausible due to the remitting resolution of the retina - that is, higher detection probabilities for more centrally presented alterations. Under conditions with the beginning and the end of the movement occurring at the same peripheral eccentricity, an even greater difference between the conditions should be observed.

However, detection probabilities of stimulus alterations at the beginning of the movement were clearly above chance level. Therefore, our attentional account cannot explain the whole variance of the observed results. The critical question is to what extent subjects are able to process two different stimuli as one stimulus; the given interpretation of the results makes sense only under this assumption. If we had used two very distinct stimuli (e.g., a big red rectangle changing into a smaller gray rectangle), subjects would probably have been quite good at detecting the alteration under these conditions. The reason for this (expected) difference in detectability is that with very distinct stimuli, different objects are instantiated that are presumably processed in parallel. It is possible that in our experiment the stimuli were still too distinct to always be processed as one single object, thus leading to an increase in the detection of alterations at the beginning of the movement. Nevertheless, the manipulation we applied in the present experiment led - as the attentional account predicts - to an unambiguous difference between the detection probability at the beginning and that at the end of the movement.

\section{GENERAL DISCUSSION}

The movement phenomenon examined here-the Fröhlich effect - consists of a mislocation of the first position of the stimulus in the direction of the movement of the stimulus. In Experiment 1, this effect was established by using a computer-generated presentation in which subjects were asked to judge the starting position of a fast-moving stimulus and the location of a stationary stimulus. It was found that subjects tended to make mislocation errors in the direction of the movement of the stimulus, whereas they were very good at localizing the stationary stimulus. The size of this mislocation was dependent on movement speed; that is, more errors were observed under conditions with higher movement speed. Futhermore, a difference between foveopetal and foveofugal movements was observed, revealing increased mislocations under conditions with foveofugal movements.

The next two experiments served as control experiments in which three factors that might influence or even cause the Fröhlich effect were tested. In Experiment 2, it was shown that neither eye movements nor structured background had an effect on the size of the mislocationat least when they were not combined in one condition, and even then, the effect was only slightly reduced. Furthermore, no influence of eccentricity on the size of the effect was observed (Experiment 3). In Experiment 4, we studied the influence of peripheral cuing. Although there was no difference in the size of the mislocation under the invalid-cue versus the no-cue condition, the Fröhlich effect was significantly reduced under valid-cue conditions. Finally, the detection probability of a stimulus modification was clearly reduced at the beginning of a movement in comparison with the end of a movement (Experiment 5).

We explained these effects by means of an attentional account. Before we discuss the present results under this view in more detail, we will check whether other interpretations are equally able to account for the basic effect and the results observed in the present experiments.

\section{Alternative Accounts of the Fröhlich Effect}

At first sight, three alternative accounts are at least conceivable. The first explanation came into use with the very early publications regarding the Fröhlich effect; the second one relates the effect to low-level and stimulus-driven processes, and, finally, the third one is based on the idea that response bias might cause the mislocation.

Historical accounts of the Fröhlich effect. As mentioned in the introduction, the original interpretation of the effect presented by Fröhlich himself was based on the idea of so-called sensation time (Fröhlich, 1923, 1929), the time needed to generate the central processing stage of a subjective "sensation." According to his interpretation, the perceived mislocation occurs because the generation of a sensation takes time, during which the stimulus moves into the window. Under the assumption that sensation time is constant, this account seems to be valid not only for the effect as such but also for its dependence on velocity ( $\mathrm{Ex}$ periment 1). But, on the other hand, there is no easy way to explain the present cuing effect with a concept like sensation time (Experiment 4): Why is sensation time reduced when a cue is presented before the stimulus? 
Furthermore, the delay caused by sensation time should occur not only at the first position of the moving stimulus but also at each single part of the movement. Thus, either a moving stimulus should not be perceived at all, or each part of the movement should be perceived with a temporal delay. In the latter case, a location error should not occur. Metzger (1932) pointed out this discrepancy in response to the original explanation presented by Fröhlich. Metzger postulated that the Fröhlich effect reflects differences in processing times of the stimulus at the entrance and at later positions in the window. The attentional account presented in the present paper also assumes these differences in processing times but extends this view to a more functional perspective.

Stimulus-driven accounts. Another alternative account might seek the causes for the mislocation at more low level processing stages. For example, when a stimulus moves across the retina, many photoreceptors and the corresponding neurons at the cortical level are stimulated within the integration time of a neuron, yet no motion blur is perceived. It has been suggested that there are motiondeblurring mechanisms to aid the visual system in the analysis of the shape of retinally moving objects (e.g., Anderson \& van Essen, 1987; Burr \& Ross, 1986; Fahle, 1995; Morgan \& Benton, 1989). Metzger (1932) already suggested that there might be a mechanism that prevents blur by inhibiting signals adjacent to the actual object. Laterarriving signals might act to inhibit earlier-arriving signals, thereby preventing blur. At the beginning of a movement, the later-arriving signals inhibit the very first parts of the movement, resulting in a mislocation in the direction of the movement and thus producing the Fröhlich effect. If it is assumed additionally that this inhibition mechanism is time constant, then it would account not only for the Fröhlich effect as such but also for the observed velocity effect.

The foveofugal-foveopetal difference (Experiment 1) can be explained by another nonattentional mechanismthe cortical magnification factor. Visual accuity is sharpest at the fovea and declines with eccentric presentation of the target. This decline has been quantitatively related to the cortical magnification factor - the linear extent of the striate cortex to which each degree of the retina projects (Cowey \& Rolls, 1974; Drasdo, 1977). For example, the increase in the threshold for motion detection with eccentricity can be compensated for by increasing the size of eccentric gratings in proportion to the cortical magnification factor (Johnston \& Wright, 1985). The solution in the periphery is not as precise as it is near the fovea, which could lead to a more pronounced mislocation in foveofugal movements than in foveopetal movements.

Data that definitely rule out both of these explanations were obtained in Experiments 3-5. In Experiment 3, no influence of eccentricity on the size of the Fröhlich effect was observed at all, while the cortical magnification account described above would predict an increase in the mislocation with increasing eccentricity. In Experiment 5, the detection probability of an alteration in the moving stimulus was found to actually decrease with more foveal presentations, whereas an increase would be expected under the influence of the cortical magnification factor. The inhibition mechanism preventing the motion blur should be sensitive for the eccentricity variation as well because fewer receptors are stimulated by a moving stimulus in the periphery than in the fovea.

Furthermore, neither explanation can account for the results obtained in Experiment 4, in which less mislocation was observed under valid-cue conditions. In sum, accounts that attribute the causes of the Fröhlich effect to pure stimulus-driven factors like the inhibition mechanism for motion blur or the cortical magnification factor cannot explain the data set obtained in the present experiments.

A response-bias account. Response bias might cause the observed mislocation in at least two ways. First, subjects might simply have produced an undershooting in their movements with the mouse cursor, which might have been caused - for example-by inadvertent arm movements. This would at least explain the mislocation observed with foveopetal movements. On the other hand, with foveofugal movements, a reversed error-that is, a mislocation in the direction opposite to the movement - should be observed, which was not the case. Additionally, the influence of such a response bias should increase with increasing eccentricity, but the results obtained in Experiment 3 showed no sensitivity to eccentricity at all.

Second, it is possible that there is some attraction arising from the end of the stimulus movement. This might shift the judgment of the starting position of the movement toward the end. On the other hand, this account can explain neither the reduction of the mislocation under cued conditions, as shown in Experiment 4, nor the reduced detection probabilities at the beginning of the movement, as observed in Experiment 5. In general, higher order response biases do not satisfactorily explain the observed results.

\section{Evaluating the Attentional Account}

The attentional account basically assumes that upon stimulus presentation, the focus of attention is shifted to the stimulus. But because this shift takes time, the stimulus will have moved a certain distance before the focus reaches it. Thus, if the first perceived position of the stimulus is determined after the completion of the focus shift, this reported location necessarily deviates from the position of its physical appearance.

This account explains the Fröhlich effect in several ways. It correctly predicts that its size depends lawfully on movement speed (Experiment 1): A faster stimulus moves a greater distance than a slower one during an attention shift. Further, it was confirmed that the processing of the moving stimulus benefits from a preceding peripheral cue that announces the subsequent movement and induces a preliminary focus shift to the position of the moving stimulus. As a consequence, the Fröhlich effect is reduced (Experiment 4). Using a detection task we were able to show that the feature information of the moving stimulus, which falls into the critical interval of the attention shift, is lost; that is, when a modification of a moving stimulus occurs at 
the beginning of the movement, it is much harder to detect than if it occurs at the end of the movement (Experiment 5).

More indirect confirmation for the attentional account arises from Experiment 2: Here, results reveal that the effect depends very little on the presentation of a structured visual background. No dependence was expected at all because the time required for an attention shift should be independent of external stimulus parameters like the visual context. Moreover, the effect does not seem to originate from eye movements; a small but reliable reduction of the Fröhlich effect was observed only if eye movements were executed in the presence of a visual background. This might result from greater accuracy under conditions in which eye movements are carried out with a visual background (Collewijn et al., 1988; Lemij \& Collewijn, 1989). In any case, there is growing evidence that eye movements and attentional mechanisms are closely linked (for a recent overview, see Van der Heijden, 1992, chap. 4.7-4.8; cf. the "premotor theory of attention" by Rizzolatti, Riggio, Dascola, \& Umiltà, 1987; Umiltà, Riggio, Dascola, \& Rizzolatti, 1991).

However, there are some unexpected findings as well: First of all, the Fröhlich effect is much larger with foveofugal movements than with foveopetal movements (Experiment 1 ). We already mentioned that this difference could point to a peripheral processing difference rather than to a central attentional one, perhaps due to sensitivity differences between foveofugal and foveopetal movements (Mateeff \& Hohnsbein, 1988; Mateeff et al., 1991) and between motion perception in the fovea and in the periphery (Finlay, 1982; Johnston \& Wright, 1985; Van de Grind, Koenderink, Van Doorn, Milders, \& Voerman, 1993). Additionally, it is true that the Fröhlich effect is reduced with a preceding peripheral cue-as expected-but this reduction is rather small (Experiment 4). One reason might be that the interval between the appearance of the cue and that of the stimulus is too short to complete the attention shift. Experiments using longer SOAs between cue and stimulus have to be done to clarify this question. On the other hand, we do not expect the Fröhlich effect to disappear completely even under optimal cuing conditions. Fröhlich himself claimed (in his original report of 1929) that the effect does not vanish completely even under conditions in which the spatial position (and the time) of the appearance of the stimulus is known in advance and the eyes are fixating on that point. This is not a general problem for an attention-shifting account since every appearance of a stimulus should trigger attentional as well as other informational processes. This is assumed to be true even if the stimulus appears at the fixated and focused position. First of all, there can be high or low attentional engagement at that position. But even if it is high, the effect should not vanish completely because all attentional mechanisms must be based on the output of other informational processes (see below). Attentional shifts by themselves are not sufficient for the perception of a stimulus. They only facilitate, prime, or enhance other processes, and-in our view - they play a significant part in the judgment of stimulus location.

\section{Conclusions}

Our attentional account for explaining the Fröhlich effect shows that selection mechanisms are not merely space based; rather, they also establish a spatial representation that is used for perceptual judgment. In this sense, attentional mechanisms are also space establishing (Müsseler, 1997; Müsseler \& Aschersleben, 1996). This was inferred from three well-known properties of visual attention: First, an attention shift is elicited by the appearance of a stimulus in the periphery. Second, this shift takes time, and third, a phenomenal representation is not available before the end of the attention shift.

The more general assumptions on which our attentional explanation is based are identical to those applied to metacontrast masking (Neumann \& Müsseler, 1990a, 1990b; see also Neumann, 1990). The basic assumption is that the presentation of a visual stimulus triggers two kinds of processes that take place simultaneously: a coding process and an attentional process. Coding processes encompass all operations that serve to create an internal code of the stimulus - for example, computing its contour, its color, size, location, and so on. An attentional process is initiated by the transient response to the appearance of the stimulus and consists of a shift of the attentional focus to the stimulus, that is, toward its approximate location. Only after this focus shift has been completed will the result of the coding processes be phenomenally represented (i.e., be available for the subject's explicit report). It is assumed that as a result of the coding processes the updating of an internal spatial map of the visual environment takes place and that the latency of this updating is shorter than that of attentional processes. Hence, it is possible that the spatial map changes while the focus shift is still under way. Because only the state of the spatial map at the end of the focus shift is phenomenally available, changes of the stimulus that occur during the focus shift will go unnoticed (cf. the comparable account for metacontrast masking by Bachmann, 1984, 1994, 1997; see also Aschersleben \& Bachmann, 1998).

This approach can be related to a broader class of stimulus arrangements: A stimulus triggers a shift of attention but is somehow modified when the shift is executed. What is perceived is not the state of the stimulus when it elicits the attention shift, but its state when the shift reaches it. In the case of the Fröhlich effect, the modification consists of the movement to a different position in space (cf. the explanation for another movement-induced effect reported in Müsseler \& Neumann, 1992). In the case of the metacontrast, the modification consists of the test stimulus being replaced by the mask. Whether this explanation can be applied to further perceptual illusions has to be clarified in future research.

\section{REFERENCES}

Adam, J. J., PaAs, F. G. W. C., Ekering, J., \& van Loon, E. M. (1995). Spatial localization: Tests of a two-process model. Experimental Brain Research, 102, 531-539.

AlLPORT, A. (1989). Visual attention. In M. I. Posner (Ed.), Foundations of cognitive sciences (pp. 631-681). Cambridge, MA: MIT Press. 
ALPERN, M. (1953). Metacontrast. Journal of the Optical Society of America, 43, 648-657.

ANDERSON, C. H., \& YAN EssEN, D. C. (1987). Shifter circuits: A computational strategy for dynamic aspects of visual processing. Proceedings of the National Academy of Sciences, 84, 6297-6301.

Aschersleben, G., \& BachmanN, T. (1998). Synchronization and metacontrast: Evidence for the dual-process attentional theory. Manuscript submitted for publication.

AsChersleben, G., \& Müsseler, J. (1998). Dissociations in the timing of stationary and moving stimuli. Manuscript submitted for publication.

BACHMANN, T. (1984). The process of perceptual retouch: Nonspecific afferent activation dynamics in explaining visual masking. Perception \& Psychophysics, 35, 69-84.

BachmanN, T. (1994). Psychophysiology of visual masking. The fine structure of conscious experience. New York: Nova Science.

BaCHMANN, T. (1997). Visibility of brief images: The dual-process approach. Consciousness \& Cognition, 6, $491-518$.

BALDO, M. V. C., \& KLEIN, S. A. (1995). Extrapolation or attention shift? Nature, 378, 565-567.

BeCKER, W., \& Fuchs, A. F. (1969). Further properties of the human saccadic system: Eye movements and correction saccades with and without visual fixation points. Vision Research, 9, 1247-1258.

BURr, D. C., \& Ross, J. (1986). Visual processing of motion. Trends in Neurosciences, 9, 304-307.

BUTLER, B. E., \& CURRIE, A. (1986). On the nature of perceptual limits in vision: A new look at lateral masking. Psychological Research, 48, 201-209.

Chastain, G. (1991). Effects of abruptly appearing clutter on a peripherally precued covert attention shift. Journal of General Psychology, 118, 31-44.

Collewijn, H., Erkelens, C. J., \& Steinman, R. M. (1988). Binocular coordination of human horizontal saccadic eye movements. Journal of Physiology, 404, 157-182.

COWEY, A., \& RoLls, E. T. (1974). Human cortical magnification factor and its relation to visual acuity. Experimental Brain Research, 21, 447-454.

CRAWFoRd, T. J., \& MÜLlER, H. J. (1992). Spatial and temporal effects of spatial attention on human saccadic eye movements. Vision Research, 32, 293-304.

Deubel, H., Wolf, W, \& Hauske, G. (1982). Corrective saccades: Effect of shifting the saccade goal. Vision Research, 22, 353-364.

DrasDo, N. (1977). The neural representation of visual space. Nature, 266, 552-556.

Driver, J., \& BAYLIS, G. C. (1989). Movement and visual attention: The spotlight metaphor breaks down. Journal of Experimental Psychology: Human Perception \& Performance, 15, 448-456.

Driver, J., MCLeOD, P., \& DienEs, Z. (1992a). Are direction and speed coded independently by the visual system? Evidence from visual search. Spatial Vision, 6, 133-147.

DrIVER, J., McLeod, P., \& Dienes, Z. (1992b). Motion coherence and conjunction search: Implications for guided search theory. Perception \& Psychophysics, 51, 79-85.

Eriksen, C. W., \& MURPhy, T. D. (1987). Movement of attentional focus across the visual field: A critical look at the evidence. Perception \& Psychophysics, 42, 299-305.

FAHLE, M. (1995). Perception of oppositely moving verniers and spatiotemporal interpolation. Vision Research, 35, 925-937.

FinKe, R. A., Freyd, J. J., \& ShyI, G. C. W. (1986). Implied velocity and acceleration induce transformations of visual memory. Journal of Experimental Psychology: General, 115, 175-188.

FINLAY, D. (1982). Motion perception in the peripheral visual field. Perception, 11, 457-462.

FreYd, J. J., \& FinKe, R. A. (1985). A velocity effect for representational momentum. Bulletin of the Psychonomic Society, 23, 443-446.

FröHLICH, F. W. (1923). Über die Messung der Empfindungszeit [Measuring the time of sensation]. Zeitschrift für Sinnesphysiologie, 54, 58-78.

FRÖHLICH, F. W. (1925). Über die Methoden der Empfindungszeitmessung in Gebiete des Gesichtssinnes [On methods to measure the time of sensation in the sense of sight]. Archiv für die gesamte Psychologie, 208, 131 .

FröHLICH, F. W. (1929). Die Empfindungszeit. Ein Beitrag zur Lehre der Zeit-, Raum- und Bewegungswahrnehmung. Jena: Fischer.
FröHLICH, F. W. (1930). Über die Messung der Empfindungszeit: Eine Erwiderung auf experimenteller Grundlage [Measuring the time of sensation: A reply on experimental basis]. Psychologische Forschung, 13, 285-288

FröHLICH, F. W. (1932). Bemerkungen zu G. E. Müllers Kritik der Empfindungszeitmessung [Remarks on the criticism of G. E. Müller of the measurement of sensation time]. Zeitschrift für Psychologie und Physiologie der Sinnesorgane, 62, 246-249.

HAGENAAR, R., \& VAN DER HEIJDEN, A. H. C. (1997). Location errors in partial-report bar-probe experiments: In search of the origin of cuealignment problems. Memory \& Cognition, 25, 641-652.

HAYES, A., \& FREYD, J. J. (1995), Attention and representational momentum (Tech. Rep. No. 95-12). Eugene: University of Oregon.

Hecht, H. (1995). Retinal, attentional, and causal aspects of illusorymotion directionality. Psychological Research, 57, 70-79.

HENSON, D. B. (1979). Investigation into corrective saccadic eye movements for refixation amplitudes of $10 \mathrm{deg}$ and below. Vision Research, 19, 57-61.

Hikosaka, O., Miyauchi, S., \& Shimojo, S. (1993a). Focal visual attention produces illusory temporal order and motion sensation. Vision Research, 33, 1219-1240.

Hikosaka, O., Miyauchi, S., \& Shimojo, S. (1993b). Voluntary and stimulus-induced attention detected as motion sensation. Perception, 22, 517-526.

Horowitz, T., \& Treisman, A. (1994). Attention and apparent motion. Spatial Vision, 8, 193-219.

HUYNH, H., \& FELDT, L. S. (1980). Performance of traditional $F$-test in repeated measure designs under covariance heterogeneity. Communication in Statistics: Theory \& Methods, A9, 61-74.

JohnSTON, A., \& WRIGHT, M. J. (1985). Lower thresholds of motion for gratings as a function of eccentricity and contrast. Vision Research, $25,179-185$.

JoNIDES, J. (1981). Voluntary versus automatic control over the mind's eye's movement. In J. B. Long \& A. D. Baddeley (Eds.), Attention and performance $I X$ (pp. 187-203). Hillsdale, NJ: Erlbaum.

Kwak, H. W., Dagenbach, D., \& EgETH, H. (1991). Further evidence for a time-independent shift of the focus of attention. Perception \& Psychophysics, 49, 473-480.

LemiJ, H. G., \& Collewis, H. (1989). Differences in accuracy of human saccades between stationary and jumping targets. Vision Research, 29, 1737-1748.

MateefF, S., \& Gourevich, J. (1983). Peripheral vision and perceived visual direction. Biological Cybernetics, 49, 111-118.

MateefF, S., \& Hohnsbein, J. (1988). Perceptual latencies are shorter for motion towards the fovea than for motion away. Vision Research, 28, 711-719.

MateefF, S., YakimofF, N., Hohnsbein, J., Ehrenstein, W. H., BoHDANECKY, Z., \& RADIL, T. (1991). Selective directional sensitivity in visual motion perception. Vision Research, 31, 131-138.

Mcleod, P., Driver, J., Dienes, Z., \& CRISP, J. (1991). Filtering by movement in visual search. Journal of Experimental Psychology: Human Perception \& Performance, 17, 55-64.

Metzger, W. (1932). Versuch einer gemeinsamen Theorie der Phänomene Fröhlichs und Hazeloffs und Kritik ihrer Verfahren zur Messung der Empfindungszeit [An attempt toward a common theory of the phenomena of Fröhlich and Hazeloff and a criticism of their methods to measure sensation time]. Psychologische Forschung, 16, 176200

MilLER, J. (1989). The control of attention by abrupt visual onsets and offsets. Perception \& Psychophysics, 45, 567-571.

Morgan, M. J., \& Benton, S. (1989). Motion-deblurring in human vision. Nature, 340, 385-386.

MüLLER, G. E. (1931). Erklärung der Erscheinungen eines mit konstanter Geschwindigkeit bewegten Lichtstreifens, insbesondere auch des Pihl-Fröhlichschen Phänomens [Explanation of the phenomenon of a lighted bar moving at a constant speed, especially the Pihl-Fröhlich phenomenen]. Zeitschrift für Sinnesphysiologie, 62, 167-202.

MüllER, H. J., \& FindLaY, J. M. (1988). The effect of visual attention on peripheral discrimination thresholds in single and multiple element displays. Acta Psychologica, 69, 129-155.

MülleR, H. J., \& RABBITT, P. M. (1989). Reflexive and voluntary orienting of visual attention: Time course of activation and resistance to 
interruption. Journal of Experimental Psychology Human Perception \& Performance, 15, 315-330.

MÜSSELER, J. (1987). Aufmerksamkeitsverlagerungen und Relativität: Ein experimenteller Beitrag zur Raum-Zeit-Wahrnehmung anhand eines Kontraktionsphänomens (Tandem-Effekt) [Attention shifts and relativity: An experimental study of the perception of space and time using a contraction phenomenon (tandem effect)]. Munich: Minerva.

Müsseler, J. (1994). Position-dependent and position-independent attention shifts: Evidence against the spotlight and premotor assumption of visual focussing. Psychological Research, 56, 251-260.

MüsSELER, J. (1997). Commentary on Stoffer and Umiltà: Focus-related or fovea-related spatial codings. In B. Hommel \& W. Prinz (Eds.), Theoretical issues in stimulus-response compatibility (pp. 209-214). Amsterdam: Elsevier.

Müsseler, J., \& Aschersleben, G. (1996). Zur Rolle visueller Aufmerksamkeitsverlagerungen bei der Etablierung einer (subjektiv berichtbaren) Raumrepräsentation [The role of attentional shifts in establishing a (subjectively reportable) spatial representation]. In B. Mertschıng (Ed.), Aktives Sehen in technischen und biologischen Systemen [Active vision in technical and biological systems] (pp. 8392). St. Augustin, Germany: Infix.

Müsseler, J., \& NeumanN, O. (1992). Apparent distance reduction with moving stimuli (tandem effect): Evidence for an attention-shifting model. Psychological Research, 54, 246-266.

Müsseler, J., VAN der HeiJden, A. H. C., Mahmud, S. H., Deubel, H., \& ERTSEY, S. (1998). Relative mislocalization of briefly presented stimuli in the retinal periphery. Manuscript submitted for publication.

NeumanN, O. (1987). Zur Funktion der selektiven Aufmerksamkeit für die Handlungssteuerung [Functions of selective attention for action planning]. Sprache und Kognition, 6, 107-125.

NeumanN, O. (1990). Visual attention and action. In O. Neumann \& W. Prinz (Eds.), Relationships between perception and action: Current approaches (pp. 227-267). Berlin: Springer-Verlag.

NeumanN, O., \& Mǘsseler, J. (1990a). "Judgement" vs. "response": A general problem and some experimental illustrations. In H. G. Geißler (Ed.), Psychophysical explorations of mental structures (pp. 445-455). Göttingen: Hogrefe.

NeUManN, O., \& MÜsseler, J. (1990b). Visuelles Fokussieren: Das Wetterwart-Modell und einige seiner Anwendungen [Visual focusing: The weather-station model and some of its applications]. In C. Meinecke \& L. Kehrer (Eds.), Bielefelder Beiträge zur Kognitionspsychologie [Bielefeld contributions to cognitive psychology] (pp. 77-108). Göttingen: Hogrefe.

O'Regan, J. K. (1984). Retinal versus extraretinal influences in flash localization during saccadic eye movements in the presence of a visible background. Perception \& Psychophysics, 36, 1-14.

POSNER, M. I. (1980). Orienting of attention. Quarterly Journal of Experimental Psychology, 32, 3-25.

POSNER, M. I., \& COHEN, Y. (1984). Components of visual orienting. In H. Bouma \& D. G. Bouwhuis (Eds.), Control of language processes. Attention and performance $X$ (pp. 531-556). Hillsdale, NJ: Erlbaum.

Remington, R., \& Pierce, L. (1984). Moving attention: Evidence for time-invariant shifts of visual selective attention. Perception \& Psychophysics, 35, 393-399

Rizzolatti, G., Riggio, L., Dascola, I., \& Umiltà, C. (1987). Reorienting attention across the horizontal and vertical meridians: Evidence in favor of a premotor theory of attention. Neuropsychologia, 25, 31-40.

RoSE, D., \& HALPERN, D. L. (1992). Stimulus mislocalızation depends on spatial frequency. Perception, 21, 289-296.

RubiN, E. (1930). Kritisches und Experimentelles zur "Empfindungszeit" Fröhlichs [Criticism and experiments on Fröhlich's concept of the time of sensation]. Psychologische Forschung, 13, 101-112.

SHEPHERD, M., \& MÜLLER, H. J. (1989). Movement versus focusing of visual attention. Perception \& Psychophysics, 86, 146-154.

Shulman, G. L., Remington, R. W., \& McLean, J. P. (1979). Moving attention through visual space. Journal of Experimental Psychology: Human Perception \& Performance, 5, 522-526.

SKAVENSKI, A. A. (1990). Eye movement and visual localization of objects in space. In E. Kowler (Ed.), Eye movements and their role in visual and cognitive processes (pp. 263-287). Amsterdam: Elsevıer.
Sperling, G., \& ReEves, A. (1980). Measuring the reaction time of a shift of visual attention. In R. S. Nickerson (Ed.), Attention and performance VIII (pp. 347-360). Hillsdale, NJ: Erlbaum.

SPERLing, G., \& Weichselgartner, E. (1995). Episodic theory of the dynamics of spatial attention. Psychological Review, 102, 503-532.

Stelmach, L. B., Herdman, C. M., \& McNeil, K. R. (1994). Attentional modulation of visual processes in motion perception. Journal of Experimental Psychology. Human Perception \& Performance, 20, 108-121.

Styles, E. A., \& AllPort, D. A. (1986). Perceptual integration of identity, location and colour. Psychological Research, 48, 189-200.

THEEUWES, J. (1991). Exogenous and endogenous control of attention: The effect of visual onsets and offsets. Perception \& Psychophysics, 49, 83-90.

Tipper, S. P., Brehaut, J. C., \& Driver, J. (1990). Selection of moving and static objects for the control of spatially directed action. Journal of Experimental Psychology: Human Perception \& Performance, 16, 492-504.

TipPer, S. P., Weaver, B., Jerreat, L. M., \& Burak, A. L. (1994). Objectbased and environment-based inhibition of return of visual attention. Journal of Experimental Psychology: Human Perception \& Performance, 20, 478-499.

TsAL, Y. (1983). Movement of attention across the visual field. Journal of Experimental Psychology: Human Perception \& Performance, 9, 523-530.

Umiltà, C., Riggio, L., Dascola, I., \& Rizzolatti, G. (1991). Differential effects of central and peripheral cues on the reorienting of spatial attention, European Journal of Cognitive Psychology, 3, 247-267.

Van De Grind, W. A., Koenderink, J. J., VAN Doorn, A. J., Milders, M. V., \& VoermaN, H. (1993). Inhomogeneity and anisotropies for motion detection in the monocular visual field of human observers. Vision Research, 33, 1089-1107.

VAN DER HeIJden, A. H. C. (1992). Selective attention in vision. London: Routledge.

VAN DER HeIJden, A. H. C., Schreuder, R., \& Wolters, G. (1985). Enhancing single-item recognition accuracy by cuing spatial locations in vision. Quarterly Journal of Experimental Psychology, 37A, 427-434.

YANTIS, S., \& GiBSON, B. S. (1994). Object continuity in apparent motion and attention. Canadian Journal of Experimental Psychology, 48 , 182-204.

\section{NOTES}

1. A somewhat similar error can be observed at the end of the movement. The so-called representational momentum describes a tendency for subjects to make judgment errors that are consistent with a continuation of the movement. This bias has been interpreted as a memory effect indicating that the mind cannot halt the representation of an object's dynamics (see, e.g., Finke, Freyd, \& Shyi, 1986; Freyd \& Finke, 1985; Hayes \& Freyd, 1995). Note that (1) the experimental procedure used with the "representational momentum" is quite different from that used with the Fröhlich effect (e.g., with respect to movement speed), and (2) the "representational momentum" interpretation cannot be applied to the beginning of the movement because the object's dynamics has to be established first (first a more extensive discussion, see Aschersleben \& Müsseler, 1998).

2. Note that a statistical comparison of the movement and the flash condition within one design is not indicated owing to the arbitrary assignment of the sign. In the flash condition, negative values indicate more foveal adjustments, while the Fröhlich effect is measured as the mislocation of the first position of a moving stimulus in the direction of the movement.

3. In order to avoid the risk of violating statistical assumptions that is present in repeated measures designs due to inhomogeneity of the variance-covariance matrix, the $F$ probabilities in the present and the following design's were corrected following Huynh and Feldt (1980).

(Manuscript received March 14, 1996; revision accepted for publication May 17, 1997.) 